\title{
Making mountains, producing narratives, or: 'One day some poor sod will write their Ph.D. on this'
}

By Katrín Lund (University of Iceland)

This paper looks at ways of narrating mountaineering experiences in Scotland. I shall examine how mountaineers organise and abstract their experiences in the form of lists, logbooks, photographs and drawings, and compare to the official listing of Scotland's topography. My argument is that when storing experiences in various material forms, mountaineers are creating their own personal topographies. These entail narratives invested through the bodily act of moving over the ground on foot. Not only are these narratives a form of play, through which mountaineers reanimate their experiences, but they are also often transformed into documents, such as logbooks, diaries, or collections of photographs and drawings. Although the topographies as created in these documents may appear to be frozen in time, I suggest that they continue to generate the movements in which they are grounded. As such they are part of an unfinished and ultimately unfinishable jigsaw puzzle. This will lead me to consider what anthropologists can learn about their own ways of organising and abstracting their experiences from examining the material culture of mountaineers.

\section{Introduction}

I like to keep all my photos together in an album... I like to keep them in an order like a story (Billy, a mountaineer)

This paper is based on fieldwork among mountaineers in Scotland and examines ways in which they narrate their experiences of hiking the Scottish hills. In 2001 I undertook fieldwork amongst mountaineers based in Aberdeen in north east Scotland, and followed them on both longer and shorter hikes into the Scottish Mountains. What these mountaineers have in common is that on their journeys they directly and indirectly follow routes and paths that have been constructed within a specific historical framework, as well as following in each other's footsteps. As such, this provides a sense of a social network of mountaineers, connected through a specific cultural activity in a particular landscape. At the same time, when examining how these mountaineers follow these different paths and routes, it appears that the landscape that they share is both 'polyvalent and multivocal' (Bender 2002:S103) and never consistent. Thus, I shall demonstrate that even though the activity of climbing the Scottish hills may create a notion of uniformity as it is shared, the landscape is still multivocal, because the activity of moving the feet over the ground is always an activity of personal narration.

I approach these narratives by examining the different ways in which they are composed and abstracted in the form of lists, logbooks, diaries, photographs, and even drawings and paintings. What these narratives have in common is that they are different ways of fixing, framing and objectifying movement over landscape that has 
been traversed on foot. I argue that although they may appear as fixed in the form in which they are kept, they nevertheless entail both the movement and the relationship that the mountaineer has with the grounds over which he or she walks. Following Lévi-Strauss, Michael Jackson (1998) explains how playing a game is sometimes motivated by the need to bring what is intangible, often daunting, under control. In agreement with this, I shall demonstrate that the practice of storing hiking experiences is a game that serves to 'miniturize, simplify, and rearrange' (ibid:31) the authoritatively established, scientifically measured and mapped topography of the Scottish Highlands to 'the scale of the self' (ibid).

This diminution was frequently expressed by the mountaineers, during the course of my fieldwork, who claimed that walking the Scottish Mountains was like bringing together pieces of a jigsaw. I learned, however, that the jigsaw puzzle is under constant construction and forms a never ending process. This is so because the process of bringing together the jigsaw puzzle is more akin to storytelling, through which the life of the mountaineer intermingles with the geographical framework that is being pieced together. Or as one of the mountaineers expressed it:

I remember in this focus group, talking about the three weeks of backpacking when I could connect different groups of mountains up with one another, and one of the great things about that was standing on the top of one mountain looking across at another group of mountains and kind of being familiar with them because I had been there. But it wasn't just that I had been there, it was because there was a story to tell about it and it was like a narrative that connected the stories together...

Thus reaching a summit is a way in which a story continues, and stories are linked together, and, thus, a summit is never an end point in itself. The jigsaw slots together as one looks over from the top of a mountain - but a story can be told again and again. And as a story may be repeated, the jigsaw pieces may be reordered and rearranged, depending on the context in which the story is being told. Hence, the narratives of piecing together the jigsaw puzzle are entangled with life as it is lived; in Ingold's words: 'There is no point at which the story ends and life begins' (2004:23).

However, although individually told, the stories in question are, as pointed out above, still shaped by how they are narrated amongst a social network of mountaineers. These are mountaineers who share the polyvalent landscape in question, by the way in which they have followed in each other's footsteps and continue to do so. Michael Jackson claims that 'stories, are a kind of a theatre where we collaborate in reinventing ourselves and authorising notions, both individual and collective, of who we are' (2002:16). Thus, although stories may miniturise, simplify and rearrange, they also re-invent and establish a notion of one's self amongst other people with shared interests. Therefore it is also important to see how the individual's stories are told in context to other stories because, as Walter Benjamin tells us, '[t]he storyteller takes what he tells from experience-his own or that reported by others. And he in turn makes it the experience of those who are listening to his tale'. Furthermore, as de Certeau points out, "narration is "established" on the basis of "primary" stories, stories [...] that already have the function of spatial legislation since they determine rights and divide up lands by "acts" or discourses about action' (1984:122, emphasis in original).

I will therefore start this paper with the primary story that created the Scottish hills as grounds to walk on, because this is the story that establishes the ground work. This is 
a story that tells how the currently 284 peaks in Scotland, collectively named Munros, were created, listed and established as designated climbing and walking grounds in Scotland. This was a legislation originally manifested by the Scottish Mountaineering Club (SMC) in Scotland, an organisation represented by nineteenth-century scholarlyorientated gentlemen who, through their activities of walking, climbing and measuring, listed, arranged and classified the Scottish landscape as grounds on which to walk. This story thus brings with it a dilemma of originality, which draws attention to the context in which the primary narratives were collected, arranged and expressed, and also to how the narratives continue to be collected, arranged and expressed.

This league of gentlemen influenced and shaped a future generation of skilled and knowledgeable enthusiasts who continued the work of climbing, collecting and arranging. Their activities often brought previously established explorations and measurements into scrutiny as they disputed amongst themselves about corrections and accuracy. Through their privileged gender and class status, these were men who maintained the already established authority, and also a certain type of ownership over the landscape as grounds on which to walk. As a result these men exchanged descriptions of mountains and how to access them that were published, often in journals local to the mountaineering clubs, but some of their publications gained more extensive readership. Consequently their authority was disturbed in the 1980s when the 'general public' started flocking to these often remote mountains. The comedian, broadcaster and passionate Munro collector Muriel Gray writes:

When the Scottish Mountaineering Club brought out a comprehensive guide cunningly titled The Munros in 1985, little did they suspect that the XR2 drivers would steer their crates away from the ski-slopes and head for the un-pisted hills. (1993:21)

Furthermore, the 'general public' were people who also claimed the grounds as theirs. This means that the SMC can rightly be blamed for having guided people into their domain, providing grounds for further contestation over the Scottish Mountains as walking grounds. The polyvalent landscape that the Scottish Mountains offer is more contested than ever before. This paper will bring out how this contestation appears through different narratives, depending on how and by whom it is narrated.

It is, however, important to note that although the landscape is contested, not just along the lines of class but also between individuals, this is still a landscape that is shared; a landscape in which mountaineers, directly and indirectly, follow the routes and paths of their mountaineering ancestors as well as each other's footsteps. It is, thus, a landscape where personal experiences and narratives intermingle with those of other mountaineers in a spatio/temporal context. This will bring up issues regarding the anthropologist who shares this same landscape in the process of walking, climbing and relating, but at the same time also carrying out participant observation. This aspect of the paper offers an insight into how anthropologists may learn about their own practices in terms of collecting, arranging and expressing - or the process of making one's own ethnographic jigsaw puzzle - and about the ways in which ethnography is a game of making, rescaling and recombining experiences in visual, textual, aural and sensual forms. 


\section{Making mountains}

My reflection on the primary story commences as I am sitting in the Edinburgh Library Archives while examining notes and letters of acknowledged Munro finalists. These are the people who wish to have their names included in the list of those who have completed climbs of the 284 mountains in the Scottish Highlands that possess the status of Munro.

The Munros are the mountains that feature in the primary story and were originally measured and classified by Sir Hugh Munro, a Scottish landowner. His inventory was established and published in the $6^{\text {th }}$ issue of the Scottish Mountaineering Club Journal in 1891, gathered through a hard labour of walking, climbing, measuring and mapping the highest peaks in the Scottish Highlands. This inventory listed the 583 tops in the Scottish Highlands that exceeded 3000 feet, including 283 tops that were granted the status of a separate mountain. The latter came to be collectively named 'the Munros' in honour of their collector. Consequently, in the context of the Scottish Highlands, it was Sir Hugh's legwork and his definitions that established the criteria of 'what makes a mountain'.

'By treating the mountains as identifiable things and establishing their status as recognised facts, his classification created an orderly idea of Scotland's highest topographical points' (Lorimer and Lund 2003:133, emphasis in original), authorised through the language of the tables themselves. However, as Mary Poovey (1998) has suggested, scientific measurements do not only shape powerful epistemologies, they are also an ambiguous category because at the same time they represent 'that which lies outside the scope of the intended generalization-beyond the categories that count' (Hastrup 2004:461). Therefore, 'the legacy of these endeavours might best be understood as the topography of the unfinished symphony' (Lorimer and Lund 2003:133) — or, in the case of this paper, 'the unfinished story'.

Since the original tables of the Munros were first published, they have been the subject of recurrent revision, alteration and reformulation. An anonymous member of the SMC states on the club's website that Munro's 'intention was to list all the Scottish Mountains of $3000 \mathrm{ft}$ and over which were of sufficient separation from neighbouring tops to merit listing'. The problem however, he claims, is that Sir Hugh forgot to leave behind a definition of what he meant by 'separation', though it is known that the character of the mountain came into it. Thus it appears that, while 'the aneroid barometer and map were Munro's trusted companions' (ibid), his judgement was also affected by his sensual experiences, stimulated by the surroundings whilst treading the Scottish grounds as an 'inhabitant of the world rather than [in] a space inside [his] head' (Ingold 2000:263).

My suggestion that the Munro Tables may be understood as the 'unfinished story' appears to contradict Benjamin's separation between forms of communication where stories become inseparable from the teller, whereas reports written to inform lack this visceral connection. Benjamin writes:

Storytelling... is itself an artisan form of communication, as it were. It does not aim to convey the pure essence of the thing, like information or a report. It sinks the thing into the life of the storyteller, in order to bring it out of him again. Thus traces of the storyteller cling to the story the way the handprints of the potter cling to the clay vessel. (1973:91) 
According to this Sir Hugh Munro appears to have removed himself from the narratives entailed in the tables whilst listing the mountains.

Ingold (2004) advances a similar argument, though from a different phenomenological perspective. He identifies a difference between telling and writing which he compares to two different modes of moving around in the world: the wayfarer's and the traveller's. Whilst the wayfarer moves along 'as life goes on' without any final destination, the traveller is transported from place to place (ibid:9). In Ingold's view, people's movements are conditioned towards travelling in our contemporary world. He compares the walk of the wayfarer to a storyline that is unbroken as the wayfarer moves along, whilst the path of the traveller appears more like a 'series of appointments than a walk' (ibid:3). Thus, according to Ingold, when the story is told it flows along and 'goes for a walk', whilst the writer 'inscribes each letter by causing the tip of the pen to perform a miniature pirouette on one spot, before shifting his hand a little to the right in order to form the next' (ibid:27). The hand moves from one point to another; letters assemble into words, words into sentences, and the combination of sentences frames the plot.

As the image above demonstrates, the way in which the Munro Tables are formed seems to support Ingold's argument. The tables appear to direct the curious reader from point to point, or peak to peak, providing necessary information for the interested 'traveller'. The page is actively constructed to ensure the reader's eyes move across the page from one row to another and then down the page from line to line. This, however, does not include the reader's experience of how the narrative has been embodied in the process of its production. What Ingold's assumption does not include is thus how the reader becomes a part of the story as he or she retraces Munro's footsteps in order to collect the information featured in the tables. What it does not include is how the mountains listed may take a shape and be located by the curious mountaineer that intends to climb them. It does not include how the landscape may be lifted up from the tables themselves in the imagination and put into context and comparison to other landscapes. What I want to emphasise here is that in order to gather his information Sir Hugh Munro took walks, and although his walks had destinations he also 'moved along' or, as pointed out above, experienced the summit as part of the story rather than as the end of a journey. Furthermore, whilst moving along he, as Ingold's wayfarer, appears to have become immersed in the surroundings as he experiences them, or, in Benjamin's observation, inseparable from the narratives - as the following quote from one of his articles published in the SMC journal shows:

There are few more beautiful places than Rothiemurchus Forest, with its fine old Scotch firs and luxuriant heather, its herds of red deer-at this season of the year very tame-its open glades and glistening tarns, its view across Loch Morlich and Glen More to the Cromdale hills, and over Strath Spey to the Monadhliaths... (Campbell 1999:24)

In order to capture Munro's full experience, we not only have to know what captured his eyes, but also how his feet touched the ground. As Merleau-Ponty claims: 'In order to perceive things we need to live them' (2002:379), which requires a focus towards the living body. When walking, the body does not simply float above the ground, but moves through a sequence of individual footsteps. Like the tip of Ingold's pen, the walker lifts his or her feet and performs one step, and then another. Often in mountaineering a single footstep becomes a matter of careful consideration and deliberation, as it can make the difference between a safe return and an accident, or 
even death. Moreover, irrespective of visual characteristics, the quality of ground can vary greatly, as Munro was aware of:

[B]ut that same luxuriant heather is uncommonly troublesome walking, every rise seems to have a corresponding dip on the other side... and the numerous tracks are all shaped like corkscrews, and all of them lead to nowhere. (Campbell 1999:24)

Thus, it appears, that for Munro, each step is an interaction between the foot and the ground and forms a fragment of a small story. This small story connects into a greater story as each journey is added to the collection. The story is not only told as it is written on the sheets of paper, but also by the movement of walking itself; in the words of de Certeau: 'The story does not express a practice. It does not limit itself to telling about a movement. It makes it. One understands it, if one enters into this movement oneself' (1984:81, emphasis in original).

\section{Moving over mountains}

There were no doubts that aspects of Sir Hugh's expeditions that had shaped the primary story were reflected through the stories recounted in the letters in which I had immersed myself whilst sitting in Edinburgh's archives. The SMC requires that those who want to have their names entered on the list of 'finalists' include information about the first and the last Munro they climbed and the time it took them to complete the task in order to frame their achievement. However, often the stories that accompanied this information seemed to be hinting at how mountaineers in Scotland do not only follow Munro's topography to complete it but also to create one of their own. At the same time, the desire to have one's name on the list of Munro finalists also points to a desire to be part of a bigger story. Sometimes this was obvious:

Bristol, 7 June 1989

...I must be in serious danger of Munrois hyperdocumentalis...

I took 152 separate expeditions (1.83 Munros per expedition)

I walked 2,692km (1,672 miles)

I climbed $171,380 \mathrm{~m}\left(562,000 \mathrm{ft}\right.$ or $106^{1 / 2}$ miles $)$

My actual walking time was about 958 hours-or enough to 40 days in the wilderness!

$69 \%$ were not occupied by other walkers (apart from companions, if any) within about $1 \mathrm{~km}$ of the summit while I was there (this seems a rather high figure?)

$78 \%$ gave me a view from the top. (Another future target might be to get a view from the other $22 \%$ !)

Sometimes these individual topographies appeared less systematic and more personal:

...I can describe my overall feelings as satisfaction and a great feeling of familiarity with the Scottish countryside. Certainly the project has taken me to places to where I would not have considered going. I can say that I have enjoyed every trip to various degrees and can look back with many good memories.

Although these two examples express different ways of telling, they also indicate that the game has come to an end and that the story has been completed. All peaks have 
been climbed and all destinations connected. At the same time, these examples both add to and re-interpret the former composition which insinuates how the collections have been personalised in the process of gathering. They are not just about being a part of a formerly established history, but also about the desire to be a part of its creation. The primary story is being continued as people continue to connect their own narratives to this history. However, and most importantly, these examples, also, indicate that the personal stories have not come to an end. The former by suggesting that the peaks that offered no views may be climbed again, and the latter through recalling good memories.

As I continued to explore the archives a small piece of paper slipped out of the folder I was about to examine. It was written by the editor of the SMC Journal and addressed to Bill, who at that time had been the Clerk of Tables, responsible for keeping the list of finalists. The note said:

\section{Bill}

For the Munro Archives!

One day some poor sod will write their Ph.D. on this!

Cheers,

Iain

I handed this note to my colleague. Our need to burst into fullblown laughter expressed both our appreciation of irony and also a sense of embarrassment. However, as I thought about this I sensed an anger towards the arrogance I felt that was coming through in this message. I also sensed that things were not adding up. I did not feel that the arrogance was directed at me as the 'poor sod', but rather towards the mountaineers who in their attempts to play by the rules established by the mountaineering authorities were eager to connect to the bigger story. I asked myself what was wrong - and by reflecting upon my own practices as an anthropologist I came to a conclusion. The way in which the SMC prefer to view the tables and lists is by excluding all evidence of subjectivity for the sake of numbers and accuracy - a phenomenon well known to anthropologists, who for centuries have been concerned with the fine line between facts and fiction.

I had been gathering a multiplicity of stories through walking, climbing, talking, as well as by playing with and reflecting on my experiences whilst organising all this disparate material into field notes, a diary and an index of photographs. De Certeau states:

To be sure, in every society, play is a stage on which the formality of practices is represented, but the condition of its possibility is that it be detached from actual social practices. On the contrary, the 'meaning' ('sens') of scriptural play, the production of a system, a space of formalization, refers to the reality from which it has been distinguished in order to change it. (1984:135, emphasis in original)

According to this it is the scriptural play that transforms experiences, formalises them and changes the reality of them. These experiences become something else. This scriptural play is not merely about the practice of writing but takes place in the context in which the script is posited. In the hands of the SMC, the Munro Tables authorise the topography of Scotland's Mountains by taking the Mountains out of context of the practice of walking that created them. The play, however, is different from the scriptural play. Although the play may be detached from the actual practices, 
such as writing up field notes in my office after a day in the hills, I am still playing with my memories. This play does not transform the experiences into something else. It rather puts them on stage to tell a story; a story in which the walking continues.

Anthropologists are not the only ones who play with memories. Mountaineers do as well, by writing logs and diaries, taking photographs and even drawing. By doing this, mountaineers, like anthropologists, create 'a miniature space where he or she decides the order of things and defines the ground rules' (Jackson 1998:29). How mountaineers define their rules has to do with how they direct their feet over the mountains, and is reflected through how they miniaturise, organise and frame their experiences. In other words, although logs, diaries and pictures may be seen to abstract movements, and are often formalised and systematised, they also make movements. They make movements because they are composed by the steps that created them. These compositions are reflected through how individual mountaineers conduct their feet whilst moving over the ground, producing a variety of ways in which they are told.

Thus, in what follows, I shall demonstrate that the difference between the play and the scriptural play is not as drastic as de Certeau wants to put it. This is so because even though pieces of information have been formalised and changed to fit the scriptural play, they can never be totally distinguished from the reality that created them, although this reality may not be immediately evident in the way in which they are formalised. This is why we need to be aware of the social and cultural context in which reality is transformed and provided with meaning in the process of playing with it.

\section{Different ways of telling}

Certainly, the work of Sir Hugh established the topography of Scotland as grounds on which to walk. How this landscape is approached in different ways by mountaineers demonstrates how mountaineers react differently to the topography with their own interpretations of it. Not all of those who finish the round of Munros report it to the SMC and the approximately 4,000 names on the list only tell part of the story. This does not mean that mountaineers stop competing amongst themselves, though they may do so according to their own rules which are often formulated in opposition to the authority of the SMC. For instance some mountaineers deliberately never climb the last Munro in order not to complete the round, and a few go as far as refusing to set foot on any mountain with Munro status, claiming that there are other and better mountains to climb. Others apply their own rules to their collections, such as only counting the tops that offered views on the day that they were climbed. Hence, how the collections, or the pieces of a jigsaw puzzle, are put together depends on how the mountaineer directs his or her feet over the mountains. What stimulates individual mountaineers is also reflected in their acts, as indicated in this passage from an interview:

Catriona: ... I think that one of the things that appeals to me the most about this is that it is just ridiculous.

Katrin: $\quad$ You think it is ridiculous....why?

Catriona: Well, why go to the top of all these hills above 3,000 feet because someone has decided to make a list of them.

Katrin: But you do it. 
Catriona: Yes that is what I think is ridiculous ... and really important because I mean how many things in life can you treat like that. I mean it's serious ... in a sense having that as an objective because I think it puts one into a space where life ... I don't know it gives me the perspective that I needed anyway.

This conversation demonstrates how the topographies that the mountaineers create are invested with their own meanings, reflected in the way the stories are organised and framed. Another young female mountaineer explains how she provides her passion for the mountain with meaning that appeals to those who do not share this passion, but at the same time offers her the opportunity to share her identity as a Munro collector.

\begin{abstract}
I think that in a way ... [a] good reason to do it [to collect the Munros] is to tell other people. You know people say 'what's the point' ... I mean my friends say to me: 'Why do you walk up the hills, you know, really just to walk down?' and if I say 'Oh it's an aim to do like all the Munros', they say: 'Oh that's quite cool' and understand it. If you just say 'because I like the hills' they don't get it.
\end{abstract}

These two snips from conversations demonstrate that collecting is as much about personal reflections as it is about sharing your passion. When I, on the other hand, sent an e-mail to ask some of the mountaineers if I could have a look at their logs, diaries or other means of collecting their mountaineering experiences, I received few responses. Originally I thought their reluctance was due to the personal nature of their records. However, when Steve brought his logbook to my office I was taken by surprise.

The systematic recording and lack of personal information puzzled me because when he handed it to me he said: 'You can burn my house and wreck my car but don't lose this, this is my life'. After handling it I could realise why, because, as someone who had gone hill walking with Steve and as someone who had climbed a few of the mountains listed in his log I felt that I could trace his footsteps. The systematic information did not, rather as in Munro's Tables, exclude the personal experiences. As a reader I could imagine the different hikes by looking at the description in their simplicity; with equals or on his own, name and height of the mountain, location of the mountain as well as weather and difficulty. As I could imagine myself following in Steve's footsteps I could see how his logbook would give Steve the opportunity to trace back his own footsteps and connect them into his story.

Ian's logbook was similar to Steve's in that it only listed and recorded the mountains he had climbed without any further information. He also confessed that the logbook was dear to him. In both these cases the systematised descriptions appear to have been disconnected from the movement over the ground that composes them. The descriptions as they are systematised move from one page to another page, from one peak to another, but when connected to each other they still provide a landscape in which a movement is performed; a movement that connects the peaks through narratives.

Although Steve and Ian provided me with examples of logbooks that may be seen as akin to how the Munro Tables and lists are formalised, there are other forms in which mountaineers archive their experiences. Jim, for example, had selected five copies of his handwritten diaries for me to have a look at when I came to his house to interview him. He has been climbing for 40 years and these five copies, featuring both stories 
about days spent in the hills as well as photographs and drawings of mountains, represented dozens of similar volumes.

Jim told me that after a day in the hills he normally jots down some notes and, when he finds the time, he writes them into a story. He told me that he keeps them primarily for his children so that they can learn more about 'the old man' when he has gone, and he also shares them with some of his closest mountaineering pals. Thus his diaries appear to be more comparable to what de Certeau defines as the play that is put on stage. His diaries are kept for personal reasons, but also to be shared. They form an important part of the story of his life, but they are, nevertheless, only to be shared with special audiences. Through this they appear to be more open to dialogue and therefore, although detached from the social practice of walking from which they are composed, they can bring that reality into being through exchanging experiences and creating narratives.

Although the diaries may be different in their forms, the nature which Steve's and Ian's logbooks and Jim's diaries share is that they all offer a reflection which brings forth the movement through which they are composed, although in different contexts. Whilst Steve's logbook allowed me to imagine myself following his footsteps, Jim's diary does so in a less abstract way. I follow in his footsteps through more actual descriptions, but I still need to depend on my imagination. However, any reflection on reality depends on imagining, and how the reality behind the play or the scriptural play appears depends on the way in which it is reflected on and imagined. Thus it is important whom the mountaineers share their stories with, and how they choose to share them. In Jim's case he shares them with his selected mountaineering pals, his children and a selected part with me as the anthropologist. Whilst Ian and Steve are willing to share their narratives with the anthropologist, it is evident that the way in which they systemise their experiences in their logs is more to be reflected on by themselves in order to bring out personal narratives.

Different forms of archiving experiences offer different ways of sharing and reflecting on reality through the imagination. Cristina, for example, told me about how she uses camera and takes photographs on her walks. Once she has had them developed she selects a single one which she pastes into an album. Then she writes a small label underneath it with the name of the mountain she was climbing on that day. 'There will always be one view I associate with that mountain, from that day', she said. So one snapshot serves to recall a whole day in the mountains. John, on the other hand, explained to me how and why he uses pastels to draw images in the mountains and said:

I suppose I like pastels because I could kind of get involved with them, they are fairly messy things, you got them on your fingers and I kind of really get involved with them in a very physical way. I like that. I suppose that is what I like to do with my mountains as well, I like to get involved with them in a physical kind of way.

The way in which John expresses how he frames and miniaturises his experiences, along with how he feels and gets involved with the mountains, throws light on the logs, lists, diaries and photographs discussed in this paper. In the drawing the mountain is frozen within the frame of the picture, but when located in his experience, as well as amongst his other drawings, the images gain a specific meaning and a place in his personal narratives. The audience can then look at the painting as a form of artwork that invites one to share this experience through a shared reality that is 
brought forth in the imagination. The logbook in which the mountaineer jots down information about height, company, weather, distance and hours spent serves a similar purpose, although its form provides a different context in which the reality behind it is brought forth. The logbook serves as an abstraction that acts as a specific type of framework for ongoing interactions with the mountains it lists. How the interactions are reflected upon depends on how the mountaineers locate themselves within their ever continuing narratives. As with Benjamin's storyteller, the narratives entailed in the jigsaw puzzle, no matter how they are archived, are inseparable from the mountaineer that performs them.

\section{Conclusion}

I have argued that although displayed within their rigid scriptural form, Munro's Tables still embody the narratives performed by Munro's feet. The stories, as told by his moving feet, appear to have disappeared because they have been taken out of context, or as de Certeau claims, they have been transformed. It is, however, known that Munro himself, despite publishing his tables, never intended to construct a popular geography of Scotland. This in itself could explain why he did not define the concept of separation, because this definition was based on his own personal reflections. Therefore, I argue, the tables remain intensely personal because they are an abstraction of his own experiences. The incompleteness of the tables is a result of how Munro himself measured his body to the grounds of the Scottish hills whilst scaling them, and as such his own jigsaw puzzle was never completed. Therefore, when the reader looks beyond the rigid framework of the mountains as listed by the SMC, they may recall Sir Hugh's personal narratives and bring forth the reality behind his collection by following his footsteps in the imagination.

I have illustrated how my own practices as ethnographer directed me towards an understanding of the difference between the scriptural play and the play that puts reality on stage, although at the same time I have attempted to lessen the gap between those two. In turn I finally want to ask what the mountaineers' practices-namely how they bring together their jigsaw puzzles - may tell us about the ethnographer's product. Michael Jackson (1998:33-34) points out that the ethnographer's task is to record and listen to stories that will later be converted into essays and monographs. He claims that the gap between the stories and the essays is that 'the storyteller testifies to life as it is lived rather than seeking to get beyond the particular situation of which he or she has direct experience in order to say something authoritative about the nature of the world' (ibid:34). In other words, the fine line between the play and the scriptural play is easily crossed through our professional practices. However, if we remind ourselves that 'life is lived at the interface of self and other' (ibid:35), we can reflect upon our own practices as anthropologists through the practices of those we encounter during the process of our fieldwork. As we play with our memories and field notes in the form of lists, diaries, photographs and even drawings, through the process of writing we must be aware of the context in which we are changing reality through our play. I suggest that as we move the tip of our pen from point to point in the process of writing we continue to follow the footsteps that originally created the narratives we are playing with. In this process we need to accept that how we reflect on the reality behind our script is always done in a process of imagining, whilst continuing to share our experiences, with our informants as well as our audience. 


\section{References}

Bender, B. 2002. Time and landscape. Current Anthropology, Supplement, 43, S103S112.

Benjamin, W. 1973. The storyteller: reflections on the works of Nikolai Leskov. In his Illuminations. London: Fontana Press.

Campbell, R.N. 1999. The Munroist's Companion. Edinburgh: Scottish Mountaineering Trust.

De Certeau, M. 1984. The Practice of Everyday Life. Berkeley: University of California Press.

Gray, M. 1993 [1991]. First Fifty: Munro-Bagging Without A Beard. London: Corgi Books.

Hastrup, K. 2004. Getting it right: knowledge and evidence in anthropology. Anthropological Theory 4(4), 455-472.

Ingold, T. 2000. The Perception of the Environment: Essays in Livelihood, Dwelling and Skill. London: Routledge.

ـ 2004. Up, across and along. Unpublished article.

Jackson, M. 1998. Minima Ethnographica: Intersubjectivity and the Anthropological Project. Chicago: University of Chicago Press.

- 2002. The Politics of Storytelling: Violence, Transgression, and Intersubjectivity. Copenhagen: Museum Tusculanum Press.

Lorimer, H. and K. Lund. 2003. Performing facts: finding a way over Scotland's mountains. In Nature Performed: Environment, Culture and Performance (eds) B. Szerszynski et al. Oxford: Blackwell Publishing.

Merleau-Ponty, M. 2002 [1962]. Phenomenology of Perception. London: Routledge.

Poovey, M. 1998. A History of the Modern Fact: Problems of Knowledge in the Sciences of Wealth and Society. Chicago: University of Chicago Press.

\section{Acknowledgements}

The research 'Pedestrian Geographies', on which this article is based, was funded by the ESRC. I am grateful to the organisers of the workshop 'From Play to Knowledge', their audience and their discussant, Sarah Green, for generous feedback on my paper. I want to thank Jeanette Edwards and Jonathan McIntosh for insightful comments, as well as the editor of Anthropology Matters and two anonymous reviewers for constructive feedback.

\section{About the author}

Katrín Lund is a lecturer at the Department of Geology and Geography, University of Iceland. She has done research in southern Spain and the Scottish Highlands. She can be contacted at kl@hi.is 